\title{
William Stanley Peart, MB BS (London) 1943, FRCP 1974, FRS 1969, KBE 1985, clinician, scientist and teacher (Born 31 Mar 1922, Died 14 Mar 2019)
}

\author{
Peter Sever ${ }^{1}{ }^{1}$
}

Received: 21 July 2020 / Revised: 16 September 2020 / Accepted: 3 November 2020 / Published online: 24 November 2020

(c) Springer Nature Limited 2020

Amongst the great British clinician scientists of the twentieth century, Stanley Peart was a giant. His international fame was based on a remarkable scientific contribution for research on the autonomic nervous system and the reninangiotensin system-two systems that play a vital role in the regulation of the circulation and the kidney. He was responsible for demonstrating that noradrenaline was the sympathetic neurotransmitter-the nature of which had eluded scientists for more than three decades and, subsequently, the nature of angiotensin, the key effector peptide hormone of the renin-angiotensin aldosterone system, and its isolation, purification and sequencing - an outstanding achievement given the limitations imposed by the technologies of the time.

He was a Fellow of the Royal Society and, in 1985, Knighted for his contribution to medicine.

Apart from science, as a teacher he was unique. Last (and by no means least), he was one of the finest clinicians I have ever encountered.

Peart's first substantial contribution arose from his work during an MRC Studentship under the supervision of Gaddum in Edinburgh in 1946. Challenged to work on sympathin, a substance putatively released from sympathetic nerves, there was uncertainty as to whether this was adrenaline or some other mediator. The question was "what actually is released from nerve endings, how could you measure it, and how could you distinguish between adrenaline and other substances released from sympathetic nerve endings, including noradrenaline?" The initial experimental model was a ewe's liver, and the effluent

Peter Sever

p.sever@imperial.ac.uk

1 National Heart \& Lung Institute, Imperial College London, ICTEM Building, Du Cane Road, London W12 0NN, UK collected used to investigate its effect on various smooth muscle preparations by bioassay. However, Peart realised that a much better model was the perfused spleen, with the rabbit ear as the bioassay for the vasoconstrictor effects of the effluent from the spleen. After a series of painstaking experiments he realised that this substance could not be adrenaline but was noradrenaline - the nature of splenic sympathin—published in the Journal of Physiology in 1949.

In 1952, George Pickering was Professor of Medicine at St Mary's in London. He was convinced that the future of hypertension research involved the identification of components of the renin-angiotensin aldosterone system (RAAS) which, based on experimental work conducted mainly in the United States, appeared to be a major candidate for the pathogenesis of hypertension. The technology involved in investigating the RAAS was not available in the laboratories at Mary's. Peart by then had returned to St Mary's and Pickering suggested that he went to the Medical Research Council laboratories at Mill Hill, where, under the direction of Charles Harington, he was exposed to the future Nobel Laureates, Rodney Porter and Martin Archer. The challenge was the nature of the blood pressure raising substance, angiotensin, and its purification. His early work involved the developmental of reverse phase chromatography and the ultimate identification by electrophoresis and spectrophotometry of the amino acid sequence of the decapepide angiotensin I. Much of this work was conducted in collaboration with Don Elliott. The final, now classic paper, was published in Nature in 1956, with a more detailed account in the Biochemical Journal.

He left Mill Hill in 1954 to return to the Medical Unit at St Mary's, where he was promoted rapidly to the role of Senior Lecturer.

At about this time, Pickering was planning to move to Oxford with Peart to accompany him, however, Peart was invited to apply for Pickering's Chair. Although the youngest applicant by far, with co-applicants including 
Douglas Black and Hugh de Wardener, he was appointed to the post.

The Unit had evolved in the direction of Pickering's research in the field of hypertension. When Peart was appointed he attracted two clinicians to the team-Bob Robertson and Jehoyda Brown, both of whom pursued his interest in hypertension, with a continuing focus on how the RAAS actually worked. The Swiss pharma company, Ciba, had synthesised angiotensin and this was used for exploratory studies in the laboratory to establish its actions. The next challenge was the isolation of renin, the rate limiting step in the activation of the RAAS. The Unit attracted visitors from around the world, particularly Australia, Italy and Greece, and the United States.

The interests of the team widened, influenced no less by, Roy Calne, Registrar on the Surgical Unit, and a future internationally renowned transplant surgeon. Ken Porter, a renal histopathologist and James Mowbray, an immunologist, shared a collective view that the team had the experience and wherewithal to start renal transplantation. This was no doubt stimulated by the recent availability of the immunosuppressive agent, azathioprine. During 1959 and 1960, renal transplantation was established at St Mary's and subsequently, one of the first series of cadaveric renal transplants, was published by the Mary's team.

Work on the renin-angiotensin system continued. The similarity of the experimental hypertension reported by Goldblatt, following occlusion of the renal artery, and the genesis of hypertension in the clinic in patients with renal artery stenosis, was obvious. New radiological techniques had been developed for the diagnosis of renal artery stenosis, and the triumvirate of Robertson, Brown and Lever, together with Peart, were in pursuit of the mediator of the hypertension and, more specifically, the identification of an assay for renin, the rate limiting enzyme in the activation of the renin-angiotensin system.

Hypertension in the early 60 s was considered the poor relation of cardiology - it probably still is - and, in contrast to the enormous national and international cardiology meetings, a small International Hypertension Group of no more than 50 participants, held its first meeting in Northern Italy. Here such names as Pickering, Page, Manger, Goldblatt, Steggs and Peart discussed and debated the key issues of the day in hypertension. This embryonic hypertension club has now evolved into an International Society with over 4,000 members.

In 1965, Brown, Robertson and Lever left the Medical Unit to establish the first Medical Research Council Unit of Hypertension in Glasgow. Back at St. Mary's, clinical medicine was a major interest of Peart's. He was absorbed by the diagnostic challenges, and there were many similarities in his approach to clinical medicine with those he had formulated from his early days in the laboratory with Gaddum.
For every patient he would generate an hypothesis, largely based on an immaculate history. Examination of the patient and clinical investigation would follow, as part of the process enabling him to reach a diagnosis and solve the problem. More than any other clinician I have ever come across, he regarded talking to the patient as being the most important part of the clinical evaluation. The patient's history, taken over some considerable time, would prompt his first question - "what ails this patient?". He regarded this, rather than the tentative diagnosis offered by the referring physician, as the fundamental basis from which his initial hypothesis would be generated.

He was also one of the first to insist upon the importance of clinical audit, which took place during a weekly meeting, and at which each and every patient who had been managed by the Medical Unit's team was presented. Management was discussed and emphasis always placed on where mistakes might have been made.

As a clinical teacher, Peart was unique. He held two formal teaching sessions a week, in addition to which, the students allocated to his firm would be expected to actively participate in his clinical ward rounds.

Combining research, clinical medicine and teaching was Peart's forte and an enormous challenge which few will take up.

During the $70 \mathrm{~s}$ and $80 \mathrm{~s}$, and resulting from his extraordinary achievements, he was invited to Chair the Medical Research Society, a society which was probably responsible for the development of academic medicine in Britain. It was a society of critically minded, senior academics, who met monthly to discuss a broad range of topics. He was appointed to membership of the Medical Research Council, where he chaired several working parties, one of which was responsible for the conduct of the two famous MRC Trials of Mild Hypertension and Hypertension in the Elderly, the outcomes of which have influenced clinical practice and guidelines to the present day.

He established joint positions with the London School of Hygiene \& Tropical Medicine in collaboration with Geoffrey Rose, a man of enormous talent and integrity-a quiet and unassuming man, deeply religious - in striking contrast to the Director of the Medical Unit! In the 1970s, he became a Wellcome Trustee. The Trust by today's standards, was extremely small. It was governed by a few decision makers with rather limited budgets—around $£ 1.5$ million per year, compared with over $£ 500$ million today. The Trustees had considerable influence over the spending in an era when patronage was the rule, and individual trustees could largely dictate the way in which the funds were dispersed.

Peart retired in 1987. The members of the unit, arranged a Festschrift for him in his favourite place on the banks of Lake Como. It was a memorable occasion attended by over 100 of his former friends and colleagues. Looking back on 
his retirement, Peart said one of the most memorable occasions was a party given to him in 1987 on his retirement by a group of surviving renal transplant patients.

Stanley Peart died age 96, after a long illness, on March 14, 2019. He was one of the last real professors of medicine-a scientist, a teacher and always a clinician. Many believe his legacy is unrivalled in British medicine. Those who followed and were fortunate to have worked with him, remember the brilliant mind, the charisma, the sense of humour and, perhaps, the bow tie and the red socks!

\section{The Stanley Peart Essay Prize}

It has been a challenge to consider how the life and work of Stanley Peart might be remembered.

It was hoped to hold a Symposium of Celebration in April this year, but this has had to be postponed until 2021, as a consequence of the Covid-19 pandemic. Separately, the British and Irish Hypertension Society agreed to mount an essay competition - the Stanley Peart Essay Prize-which this year is funded by the Foundation for Circulatory Health.
The task this year was to write an essay entitled "The treatment of the hypertensive patient in the year 2030". Young investigators were invited to submit their essays to a panel of judges under the chairmanship of the President, Professor Una Martin. We are delighted that the Journal is publishing the essays submitted by the winners, Dr Spoorthy Kulkarni, Cambridge, and the runner up, Dr Roshni Bhudia, Cambridge, both of whom are to be congratulated for their insightful accounts of how hypertension might be managed in the year 2030.

The full version of the Stanley Peart Obituary was published in Hypertension. 2019. PMID: 31680562

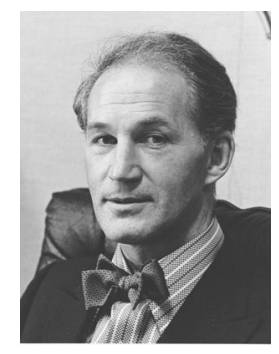

